\title{
RELATIONSHIP BETWEEN STEM BIOMASS WITH HEIGHT AND DIAMETER OF Pinus caribaea IN THE YAGIRALA FOREST RESERVE
}

\author{
A M R Haripriya and S M C U P Subasinghe \\ Department of Forestry and Environmental Science, \\ University of Sri Jayewardenepura
}

The biomass is an important measurement in commercial forestry maintained to produce pulp, paper, chips, fuel wood products etc. The estimation of biomass of the tree is not an easy task and a few studies were carried out so far on this problem.

The present study was conducted in 25 years old pine plantation in Yagirala Forest Reserve, situated in low country wet zone. According to the geographical differences of the plantation, stratified random sampling was carried out and two 0.05 ha circular plots were established in each stratum. Altogether 6 plots were used for the data collection. The diameter at the breast height $(\mathrm{dbh})$ and total height were measured for all the trees in these plots.

Biomass of the tree was estimated by extracting core samples at the breast height and mid height of the tree. The density of the core samples was estimated using oven dry weight and green volume of the core samples. When tested, there was no significant difference of density along the stem. Therefore stem biomass was estimated using the density at breast height. Also there was no significant density difference between three sites.

The regression analysis was used with pooled data to find out the relationship between the stem biomass with the tree diameter and height. Using variables of stem volume $(W)$, total height $(h)$, diameter at breast height $(d)$ and their transformations, several models were developed. The best model was selected by testing for the $\mathrm{R}^{2}$ value, standard residual distribution, modelling efficiency and bias. The best relationship for the stem biomass, total height and diameter at breast height was given by the following equation, which has $\mathrm{R}^{2}$ value of 90.3 .

$$
\log W=-0.917+2.08 \log d+0.0195 h
$$

Proceedings of the Ninth Annual Forestry and Environment Symposium 2003 of the Department of Forestry and Environmental Science, University of Sri Jayewardenepura, Sri Lanka 